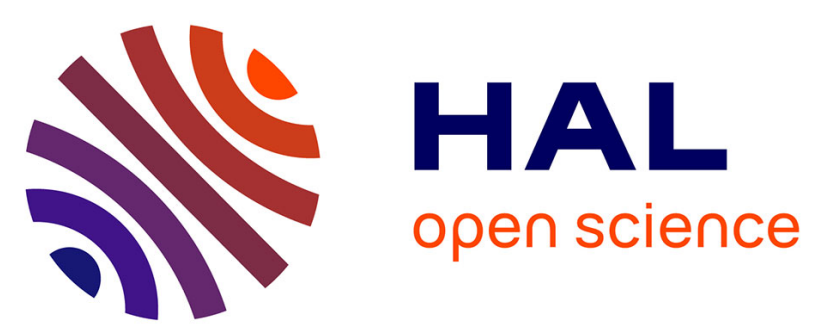

\title{
First observations of SO2 above Venus' clouds by means of Solar Occultation in the Infrared
}

D. Belyaev, Oleg Korablev, A. Fedorova, Jean-Loup Bertaux, A.-C. Vandaele, Franck Montmessin, A. Mahieux, V. Wilquet, R. Drummond

\section{- To cite this version:}

D. Belyaev, Oleg Korablev, A. Fedorova, Jean-Loup Bertaux, A.-C. Vandaele, et al.. First observations of SO2 above Venus' clouds by means of Solar Occultation in the Infrared. Journal of Geophysical Research. Planets, 2008, 113 (E5), pp.E00B25. 10.1029/2008JE003143 . hal-00350093

\section{HAL Id: hal-00350093 https://hal.science/hal-00350093}

Submitted on 23 Apr 2016

HAL is a multi-disciplinary open access archive for the deposit and dissemination of scientific research documents, whether they are published or not. The documents may come from teaching and research institutions in France or abroad, or from public or private research centers.
L'archive ouverte pluridisciplinaire HAL, est destinée au dépôt et à la diffusion de documents scientifiques de niveau recherche, publiés ou non, émanant des établissements d'enseignement et de recherche français ou étrangers, des laboratoires publics ou privés. 


\title{
First observations of $\mathrm{SO}_{2}$ above Venus' clouds by means of Solar Occultation in the Infrared
}

\author{
D. Belyaev, ${ }^{1}$ O. Korablev, ${ }^{1}$ A. Fedorova, ${ }^{1}$ J.-L. Bertaux, ${ }^{2,3}$ A.-C. Vandaele, ${ }^{4}$ \\ F. Montmessin, ${ }^{2,3}$ A. Mahieux, ${ }^{4}$ V. Wilquet, ${ }^{4}$ and R. Drummond ${ }^{4}$ \\ Received 18 March 2008; revised 29 July 2008; accepted 2 September 2008; published 31 December 2008.
}

[1] Solar Occultation in the Infrared (SOIR) is a part of the Spectroscopy for Investigation of Characteristics of the Atmosphere of Venus (SPICAV)/SOIR occultation experiment on board Venus Express dedicated to the study of gaseous and aerosol vertical structure of Venus' mesosphere. SOIR is an echelle spectrometer with acoustooptic selection of diffraction orders operating in the wavelengths range of $2.2-4.3 \mu \mathrm{m}$ at high spectral resolution $(\lambda \Delta \lambda \sim 20,000)$. Detection of minor constituents such as $\mathrm{CO}, \mathrm{H}_{2} \mathrm{O}, \mathrm{HDO}$, $\mathrm{HCl}, \mathrm{HF}$, and $\mathrm{SO}_{2}$, at altitudes between 65 and $130 \mathrm{~km}$ has been demonstrated. We report results from a series of six occultations with observations of the 4- $\mu \mathrm{m} \mathrm{SO}_{2}$ band at latitudes $69^{\circ}-88^{\circ} \mathrm{N}$ and $23^{\circ}-30^{\circ} \mathrm{N}$. It is the first time when the vertical distribution of $\mathrm{SO}_{2}$ is retrieved above the clouds with the help of solar occultation direct method. The sulfur dioxide transmission spectrum is measured on a background of strong $\mathrm{CO}_{2}$ absorption.

Each retrieved vertical profile of $\mathrm{SO}_{2}$ is characterized by few points; the mixing ratio of $\mathrm{SO}_{2}$ being $\sim 0.1 \mathrm{ppm}$ with scale height $1 \pm 0.4 \mathrm{~km}$ for polar measurements (evening observations) and $\sim 1 \mathrm{ppm}$ with scale height $3 \pm 1 \mathrm{~km}$ at low latitudes (morning observations) at the altitude of about $70 \mathrm{~km}$. Upper limits of $<\sim 0.05 \mathrm{ppm}$ are established around $75 \mathrm{~km}$.

Citation: Belyaev, D., O. Korablev, A. Fedorova, J.-L. Bertaux, A.-C. Vandaele, F. Montmessin, A. Mahieux, V. Wilquet, and R. Drummond (2008), First observations of $\mathrm{SO}_{2}$ above Venus' clouds by means of Solar Occultation in the Infrared, J. Geophys. Res., 113, E00B25, doi:10.1029/2008JE003143.

\section{Introduction}

[2] Sulfur dioxide is an important component of Venus' atmosphere because this gas is the chemical precursor of $\mathrm{H}_{2} \mathrm{SO}_{4}$ droplets clouds which completely enshroud Venus. Any significant change in $\mathrm{SO}_{2}$ above and within the clouds of Venus can affect photochemistry and dynamics of the clouds [Esposito et al., 1997]. Moreover, sulfur dioxide behavior in the atmosphere may be an indicator of possible geological activity on the surface of the planet.

[3] Sulfur dioxide in the Venusian atmosphere was first detected from ultraviolet Earth-based observations of the solar light scattered by cloud particles and Rayleigh scattering with a high spectral resolution $\sim 0.1 \mathrm{~nm}$ [Barker, 1979], and the detected mixing ratio was $0.02-0.5 \mathrm{ppm}$ at the cloud top. Space-based identifications of $\mathrm{SO}_{2} \mathrm{UV}$ absorption followed soon from Pioneer Venus orbiter (PV) [Stewart et $a l .$, 1979] and International Ultraviolet Explorer (IUE) [Conway et al., 1979]. The first one provided a retrieval of $\mathrm{SO}_{2}$ vertical column density of about $10^{17} \mathrm{~cm}^{-2}$ with a

\footnotetext{
${ }^{1}$ Space Research Institute, Moscow, Russia.

${ }^{2}$ Service d'Aéronomie du CNRS, Verrières-le-Buisson, France.

${ }^{3}$ Also at Institut Pierre Simon Laplace, Université de Versailles-SaintQuentin, Guyancourt, France.

${ }^{4}$ Belgian Institute for Space Aeronomy, Brussels, Belgium.

Copyright 2008 by the American Geophysical Union. 0148-0227/08/2008JE003143
}

spectral resolution of $1.3 \mathrm{~nm}$ [Esposito et al., 1979] while the second one registered a column density of $4 \times 10^{16} \mathrm{~cm}^{-2}$ (0.1-0.8 ppm above the clouds) with a higher resolution of $0.3 \mathrm{~nm}$. These abundances were larger by orders of magnitude than previously established upper limits delivered from rocket soundings in 1967 [Jenkins et al., 1969; Anderson et al., 1969] and Orbiting Astronomical Observatory (OAO) in 1972 [Owen and Sagan, 1972]. Continuous observations of the PV UV spectrometer from 1978 to 1986 showed a steady decline of the cloud top $\mathrm{SO}_{2}$ content down to 20 $50 \mathrm{ppb}$ [Esposito et al., 1988]. This decline was confirmed by 1987-1988 IUE observations [Na et al., 1990]. Inbetween observations of sulfur dioxide in the UV range were made in 1983 by a balloon-borne spectrophotometer with a resolution of $0.4 \mathrm{~nm}$ [Parisot et al., 1986]. These measurements gave a mixing ratio of $70 \mathrm{ppb}$ and, hence, confirmed the decrease of $\mathrm{SO}_{2}$ at that moment. Later rocket measurements in the UV range with a resolution of $0.2 \mathrm{~nm}$ resulted in $\mathrm{SO}_{2}$ content of $80 \pm 40 \mathrm{ppb}$ in 1988 and $120 \pm$ $60 \mathrm{ppb}$ at the equator in 1991 [McClintock et al., 1994; $\mathrm{Na}$ et al., 1994]. That was in agreement with PV and IUE results. One more UV measurement was made in 1995 from Hubble Space Telescope (HST) [Na and Esposito, 1995]. The $\mathrm{SO}_{2}$ abundance was $20 \pm 10 \mathrm{ppb}$ that is lower than values obtained in 1978-1991 by a factor of 2-5 again confirming the decrease of $\mathrm{SO}_{2}$.

[4] Sulfur dioxide was also measured in the infrared spectral range by the Fourier Spectrometer on board Venera 
15 orbiter [Moroz et al., 1985]. The instrument detected $\mathrm{SO}_{2}$ absorption bands at 519,1150, and $1360 \mathrm{~cm}^{-1}$ with a spectral resolution of $5-7 \mathrm{~cm}^{-1}$. Nadir measurements covered the high northern latitudes almost completely; the sounding at altitude was around $69 \mathrm{~km}$ (40 mbar pressure). A strong dependence of $\mathrm{SO}_{2}$ content on latitude was reported: from $20 \mathrm{ppb}$ at equator to $0.5 \mathrm{ppm}$ in polar region. These data were found consistent with Pioneer Venus and IUE results [Zasova et al., 1993], taking into account the different effective sounding altitudes.

[5] The goal of this paper is to present the first results concerning the detection of sulfur dioxide above the Venus' cloud top by means of solar occultation in the infrared range using SOIR on board Venus Express orbiter (VEX) [Titov et al., 2006; Bertaux et al., 2007] The use of solar occultations probing (at the planet terminator) allows us to measure the atmospheric transmission and to retrieve information about the vertical structure and the composition at altitudes between 65 and $130 \mathrm{~km}$ (see Vandaele et al. [2008] and Fedorova et al. [2008] for the description of the technique and results for other key constituents of the Venus atmosphere). The slant density of $\mathrm{SO}_{2}$ is rapidly decreasing with altitude because of photolysis by sunlight. In occultation geometry this gas originating from the clouds is, therefore, expected to be observed only near the cloud top. The high photometric accuracy of SOIR instrument allows to measure transmitted spectrum down to slant optical thicknesses of $\tau \sim 6$ (from aerosols), making it possible to detect $\mathrm{SO}_{2}$ with a satisfactory signal/noise ratio down to $68 \mathrm{~km}$.

\section{Instrument}

[6] SOIR instrument is a compact high-resolution infrared echelle spectrometer, in which an acoustooptical tunable filter (AOTF) is used for preliminary sorting of echelle diffraction orders [Korablev et al., 2004; Nevejans et al., 2006]. The instrument with spectral range $2300-4500 \mathrm{~cm}^{-1}$ and resolution of $\sim 0.15 \mathrm{~cm}^{-1}$ is capable to detect important minor gaseous constituents such as $\mathrm{CO}, \mathrm{SO}_{2}, \mathrm{HCl}, \mathrm{HF}, \mathrm{H}_{2} \mathrm{O}$ and HDO by means of solar occultation. The detailed description of the spectrometer, its in-flight performance, and calibrations are given in papers by Nevejans et al. [2006] and Mahieux et al. [2008]. We describe briefly the main parameters of the instrument, and some details related to $\mathrm{SO}_{2}$ detection.

[7] The spectrometer's rectangular field of view (FOV) is 30 arc minutes in spatial dimension, by 2 arc min in spectral dimension. This FOV is projected into 256 by 320 elements of an $\mathrm{HgCdTe}$ matrix detector. The elements of the detector, corresponding to the height of the slit are binned to form two groups each corresponding to 15 arc minutes. The angular diameter of the Sun from Venus orbit is $\sim 40$ arc $\min$. The width of the slit corresponds to $2 \operatorname{arc} \min$. The spectrum is dispersed by the echelle onto the 320 spectral elements of the detector. The resolution of the echelle spectrometer, operating in diffraction orders $104-204$ is $0.15 \mathrm{~cm}^{-1}$. The $\mathrm{SO}_{2}$ absorption bands were studied in the $4-\mu \mathrm{m}$ range $\left(2500 \mathrm{~cm}^{-1}\right)$, corresponding to 111 and 112 diffraction orders. The AOTF serves as an electrically tuned filter with a passband of $\sim 25 \mathrm{~cm}^{-1}$, which is slightly larger than the widths of a single diffraction order [Mahieux et al., 2008]. Moreover, the spectral profile of the AOTF trans- mittance with side lobes includes also a few adjacent orders. Therefore, the measured spectrum contains a mixture of several orders. In the present study we consider the contribution of five nearby diffraction orders from each side. Calibration of the AOTF spectral function is made as described by Mahieux et al. [2008].

\section{Calculations}

\subsection{Modeling of Transmission Spectra}

[8] The solar occultation technique allows measuring the atmospheric transmission at the terminator of a planet (either sunrise or sunset). For a spacecraft moving along its orbit the Sun is occulted by the planetary limb. During the occultation the FOV of the spectrometer is maintained by the inertial spacecraft attitude in Sun direction. A solar spectrum, measured out of the atmosphere (in our case, above $\sim 150 \mathrm{~km}$ of tangent altitude), is considered as a reference spectrum $F_{0}(\nu)$ ( $\nu$ denotes wave number). Then, the instrument registers a set of solar spectra $F(\nu, z)$, passed through the atmosphere at various altitudes of the target point $\mathrm{z}$. The solar occultation method is self-calibrated with respect to the atmospheric transmission which for a given altitude $z$ is determined as:

$$
T(\nu, z)=F(\nu, z) / F_{0}(\nu) .
$$

The strongest absorption band of $\mathrm{SO}_{2}$ within the spectral range of SOIR is located around $4 \mu \mathrm{m}\left(2500 \mathrm{~cm}^{-1}\right)$. This range is contaminated by a strong absorption of $\mathrm{O}^{16} \mathrm{C}^{12} \mathrm{O}^{18}$ isotope of $\mathrm{CO}_{2}$ (20003-00001 transition) and the $\mathrm{SO}_{2}$ spectrum is registered on the background of the $\mathrm{CO}_{2}$ absorption (Figure 1). The contribution of other atmospheric gases such as $\mathrm{H}_{2} \mathrm{O}$ and its isotopes, $\mathrm{HCl}$, $\mathrm{HF}$ is negligible in this range; among the molecules listed in HITRAN 2004 spectral database [Rothman et al., 2005] the strongest absorption is expected from HDO, and it does not exceed $10^{-2}$. The transmission may be then theoretically expressed by the following combination:

$$
T(\nu, z)=T_{\mathrm{CO} 2}(\nu, z) T_{\mathrm{SO} 2}(\nu, z) T \tau(\nu, z),
$$

where

$$
\begin{aligned}
& T_{\mathrm{CO} 2}(\nu, z)=\exp \left[-2 \int_{z}^{\infty} \sigma_{\mathrm{CO} 2}(T(l), p(l)) n_{\mathrm{CO} 2}(l) d l\right] \\
& T_{\mathrm{SO} 2}(\nu, z)=\exp \left[-2 \int_{z}^{\infty} \sigma_{\mathrm{SO} 2}(T(l), p(l)) n_{\mathrm{SO} 2}(l) d l\right], \\
& T_{\tau}(\nu, z)=\exp \left[-\tau_{a}(\nu, z)\right] .
\end{aligned}
$$

Integration is performed along the optical trajectory $l$ in the atmosphere. Gaseous local density $n(l)$ is defined from respective slant density using the "onion peeling" method [Bézard et al., 1987; Vandaele et al., 2008] assuming spherical symmetry of the atmosphere, and hydrostatic equilibrium. The absorption cross section $\sigma_{i}(T, p)$ can be 


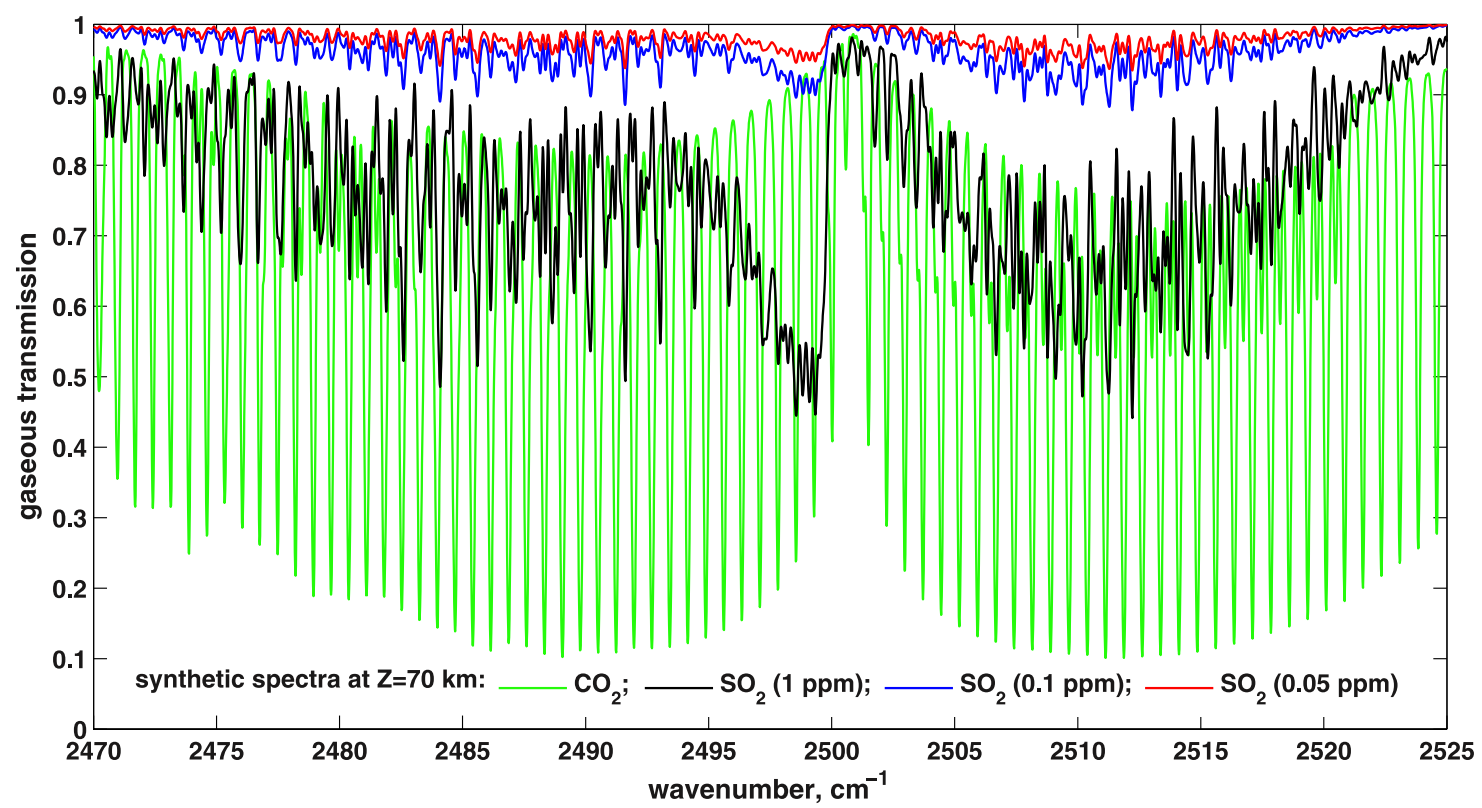

Figure 1. Synthetic spectra of $\mathrm{SO}_{2}$ (for several mixing ratios, 0.05 (red), 0.1 (blue), and 1 ppm (black)) are presented at occultation altitude of $70 \mathrm{~km}$ on a background of $\mathrm{CO}_{2}$ spectrum (green curve) in range $2470-2525 \mathrm{~cm}^{-1}$ corresponding to the echelle orders 111 and 112 .

calculated using line-by-line simulations of gaseous absorption using line parameters from spectroscopic database. The slant optical thickness of aerosol $\tau_{a}(\nu, z)$ is determined from the occultation procedure as

$$
\tau_{a}(\nu, z)=-\ln \left(T_{a}(\nu, z)\right),
$$

where $T_{a}(\nu, z)$ is the continuum derived from the measured transmission spectra (equation (1)) following a retrieval procedure described below. In the present analysis we do not take into account the atmospheric refraction, which may introduce an error of a fraction of $\mathrm{km}$ into the effective sounded attitude at $70 \mathrm{~km}$ [Mahieux et al., 2008].

[9] All necessary spectroscopic gaseous parameters for calculations in equation (2) are taken from HITRAN 2004 database. Within the spectral range of interest (2450$2550 \mathrm{~cm}^{-1}$ ) the $\mathrm{SO}_{2}$ absorption is observed on the background of carbon dioxide absorption dominated by isotopic band of ${ }^{16} \mathrm{O}^{12} \mathrm{C}^{18} \mathrm{O}(628)$, and the mixing ratio of $\mathrm{SO}_{2}$ is derived with respect to this isotope. The isotopic ratio of 628 isotope on Earth is $3.9 \times 10^{-3}$, and it is almost the same on Venus with an accuracy of $\sim 5 \%$ (as discussed by Vandaele et al. [2008]). Further in the text, for simplicity, $\mathrm{CO}_{2}$ will signify the 628 isotope.

[10] A set of $\mathrm{SO}_{2}$ synthetic spectra of Venus atmospheric transmission in occultation geometry for the tangent altitude of $70 \mathrm{~km}$ is presented together with the $\mathrm{CO}_{2}$ model (including all isotopes) in Figure 1. We assumed VIRA-2 empirical atmospheric model [Moroz and Zasova, 1997; Zasova et al., 2006] for atmospheric density and uniformly mixed $\mathrm{SO}_{2}$ with several relative abundances: $0.05,0.1$ and $1 \mathrm{ppm}$ (from the VIRA data this value is $0.1 \mathrm{ppm}$ for the same altitude). In Figure 2 the spectrum of the combined $T_{\mathrm{CO} 2} T_{\mathrm{SO} 2}$ transmission (blue curves for 111 and 112 orders) at the altitude $68 \mathrm{~km}$ is modeled taking into account contribution of adjacent diffraction orders of the echelle spectrometer. Separate $\mathrm{CO}_{2}$ and $\mathrm{SO}_{2}$ simulations with the orders mixing are shown as well (green and black curves, respectively).

\subsection{Algorithm of Fitting}

[11] As it is evident from the synthetic model (Figures 1 and 2), the $\mathrm{SO}_{2}$ absorption features are overlapped by a strong $\mathrm{CO}_{2}$ structure. Not a single isolated line of $\mathrm{SO}_{2}$ is available for the analysis. Therefore, a combined synthetic model $T_{\mathrm{CO} 2} T_{\mathrm{SO} 2}$ including extinction and the mixing of diffraction orders was compared to the measured spectrum at each altitude. The fitting was performed in the spectral range of $2483-2500 \mathrm{~cm}^{-1}$ in the diffraction order 111, and of $2505-2523 \mathrm{~cm}^{-1}$ in the order 112 . The procedure to compute the synthetic model including aerosol extinction and the order mixing consists of the following steps:

[12] 1. Computing of theoretical $T_{\mathrm{CO} 2}(\nu, z)$ and $T_{\mathrm{SO} 2}(\nu, z)$ transmissions separately for a specified altitude $z$. The $\mathrm{CO}_{2}$ density $n_{\mathrm{CO} 2}$ and the $\mathrm{SO}_{2}$ mixing ratio $f_{\mathrm{SO} 2}=n_{\mathrm{SO} 2} / n_{\mathrm{CO} 2}$ are considered as variable parameters.

[13] 2. Combined transmission $T_{\mathrm{CO} 2 \mathrm{SO} 2}(\nu, z)=T_{\mathrm{CO} 2}(\nu, z)$ $T_{\mathrm{SO} 2}(\nu, z)$ is calculated taking into account the mixing of echelle orders with the contribution of five diffraction orders from each side: $T_{\mathrm{CO}_{2} \mathrm{SO}_{2}}(\nu, z) \rightarrow T_{\mathrm{CO} 2 \mathrm{SO}_{2}}^{\text {ord }}(\nu, z)$. The full spectral range which contributes to the combined spectrum amounts to $2370-2640 \mathrm{~cm}^{-1}$.

[14] 3. Two "differential" continua $I_{\text {dif }}^{\bmod }(\nu, z)$ and $I_{\text {dif }}^{\text {data }}(\nu, z)$ are extracted from both theoretical $T_{\mathrm{CO}_{2} \mathrm{SO}_{2}}^{\text {ord }}(\nu, z)$ and measured $T_{\text {data }}(\nu, z)$ spectra (equation (1)), in a similar manner as in the method of differential optical absorption spectroscopy (DOAS) [Plat, 1994]. Continuum curves are determined at a number of spectral intervals between absorption lines where absorption is minimal. Square polynomial interpolation is used in between. 


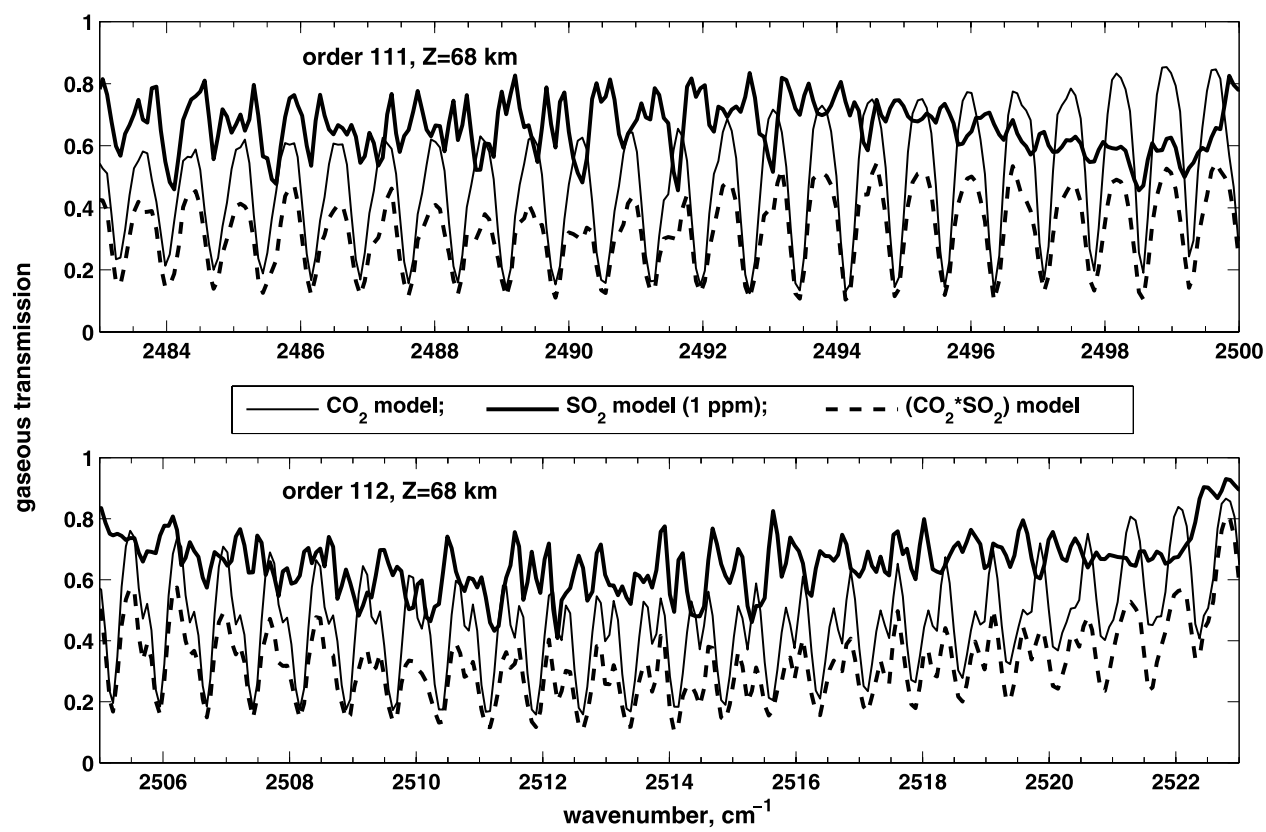

Figure 2. Synthetic spectra of combined transmission $\left(\mathrm{CO}_{2} * \mathrm{SO}_{2}\right)$ (dashed curves) are presented for echelle orders (top) 111 and (bottom) 112 at the altitude of $68 \mathrm{~km}$ together with separated models of $\mathrm{CO}_{2}$ (thin curves) and $\mathrm{SO}_{2}$ (for $1 \mathrm{ppm}$; thick curves). All the spectra are calculated taking into account the contribution from \pm 5 adjacent echelle orders due to nonzero side lobes of the AOTF passband function.

[15] 4. Calculation of additional extinction factor (due to attenuation in the atmosphere) $A(\nu, z)=1 / I_{\text {dif }}^{\bmod }(\nu, z)$ that describes difference between gaseous "differential" and aerosol continua. The aerosol continuum is then defined as $T_{\text {aer }}(\nu, z)=I_{\text {dif }}^{\text {data }}(\nu, z) A(\nu, z)$, and, therefore, we can find the atmospheric optical thickness $\tau_{a}(\nu, z)$ following equation (3).

[16] 5. Finally, a combined synthetic transmission is found as $T_{\bmod }(\nu, z)=T_{\mathrm{CO} 2 \mathrm{SO} 2}^{\text {ord }}(\nu, z) T_{\tau}(\nu, z)$ (equation (2)).

[17] The resulted synthetic model $T_{\bmod }(\nu, z)$ is fitted to each measured spectrum to retrieve the values of $n_{\mathrm{CO} 2}$ and $f_{\mathrm{SO} 2}$ corresponding to the minimum of the function

$$
S\left(n_{\mathrm{CO} 2}, f_{\mathrm{SO} 2}\right)=\sum_{i}\left(\frac{T_{\text {data }}\left(\nu_{i}, z\right)-T_{\mathrm{mod}}\left(\nu_{i}, z\right)}{\sigma_{i}}\right)^{2},
$$

where $i$ is a number of a spectral point $(1-320), \sigma_{i}$ is the error corresponding to this point. The aerosol optical thickness $\tau_{a}$ is defined as a by-product of the retrieval at each altitude. We will use value $\tau_{a}=1$ as reference to define the cloud top level (though it is rather the top of the haze, above the classical cloud deck).

\section{Occultations}

\subsection{Strategy of Observations}

[18] From December 2006 to August 2007 more then 20 occultations covering the spectral range relevant to $\mathrm{SO}_{2}$ were performed. We have analyzed a subset of six occultations available before July 2007. Two measurements correspond to low latitudes $\left(23^{\circ}-30^{\circ} \mathrm{N}\right)$ and four to high latitudes of Venus $\left(69^{\circ}-88^{\circ} \mathrm{N}\right)$ (see Table 1). Observations nearby the pole were made from the closest distance to the limb ( $2000 \mathrm{~km}$, that corresponds to altitude resolution about $1 \mathrm{~km}$ ), while observations at low latitudes were made from larger distances $(>5000 \mathrm{~km}$ with vertical resolution of $>3 \mathrm{~km}$ ). During an occultation two spectra are recorded simultaneously by two bins of the detector corresponding to

Table 1. Tabulation of Analyzed Occultations With Main Parameters of Observation ${ }^{\mathrm{a}}$

\begin{tabular}{|c|c|c|c|c|c|c|c|c|c|c|}
\hline Orbit (in/eg) & Date & Local Time & Lat & Lon & Dist, km & $\begin{array}{l}\text { Spectral Range, } \\
\mathrm{cm}^{-1} \text { (Order) }\end{array}$ & $\begin{array}{c}\text { Altitude } \\
\text { Range, km }\end{array}$ & $\begin{array}{c}\text { Altitude of } \\
\tau=1, \mathrm{~km}\end{array}$ & $f_{\mathrm{SO} 2}, \mathrm{ppm}$ & $H_{\mathrm{SO} 2}, \mathrm{~km}$ \\
\hline 235 (in) & 12 Dec 2006 & 0149 & $88^{\circ}$ & $309^{\circ}$ & 2130 & $2483-2500(111)$ & 68 & 76 & 0.5 & - \\
\hline 244 (in) & 21 Dec 2006 & 1953 & $85^{\circ}$ & $246^{\circ}$ & 2242 & $2483-2500(111)$ & 68 & 75 & 0.7 & - \\
\hline 251 (in) & 28 Dec 2006 & 1916 & $82^{\circ}$ & $260^{\circ}$ & 1741 & $2505-2523(112)$ & $68-71$ & 76 & 0.3 & 1.1 \\
\hline 262 (in) & 8 Jan 2007 & 1830 & $69^{\circ}$ & $282^{\circ}$ & 2274 & $2483-2500(111)$ & $69-72$ & 75 & 0.7 & 0.8 \\
\hline $434(\mathrm{eg})$ & 29 Jun 2007 & 0558 & $30^{\circ}$ & $265^{\circ}$ & 5502 & $2483-2500(111)$ & $70-76$ & 83 & 1 & 2.8 \\
\hline $435(\mathrm{eg})$ & 30 Jun 2007 & 0558 & $23^{\circ}$ & $267^{\circ}$ & 6179 & $2505-2523(112)$ & $72-78$ & 83 & 3 & 3.3 \\
\hline
\end{tabular}

${ }^{\mathrm{a}}$ Orbit (in/eg), number of orbit (ingress/egress); Date, date of observation; Local time, local time on Venus; Lat, latitude; Lon, longitude; Dist, distance to limb; Spectral range (order), spectral range $\left(\mathrm{cm}^{-1}\right)$ with corresponded echelle order; Altitude range, altitude range of $\mathrm{SO}_{2}$ detection $(\mathrm{km})$; Altitude at $\tau=1$, altitude at which optical thickness is one; $f_{\mathrm{SO} 2}$, mixing ratio of $\mathrm{SO}_{2}(\mathrm{ppm})$ at level of $\sim 69 \mathrm{~km} ; H_{\mathrm{SO} 2}$, scale height of $\mathrm{SO}_{2}$ at $70 \mathrm{~km}$. 


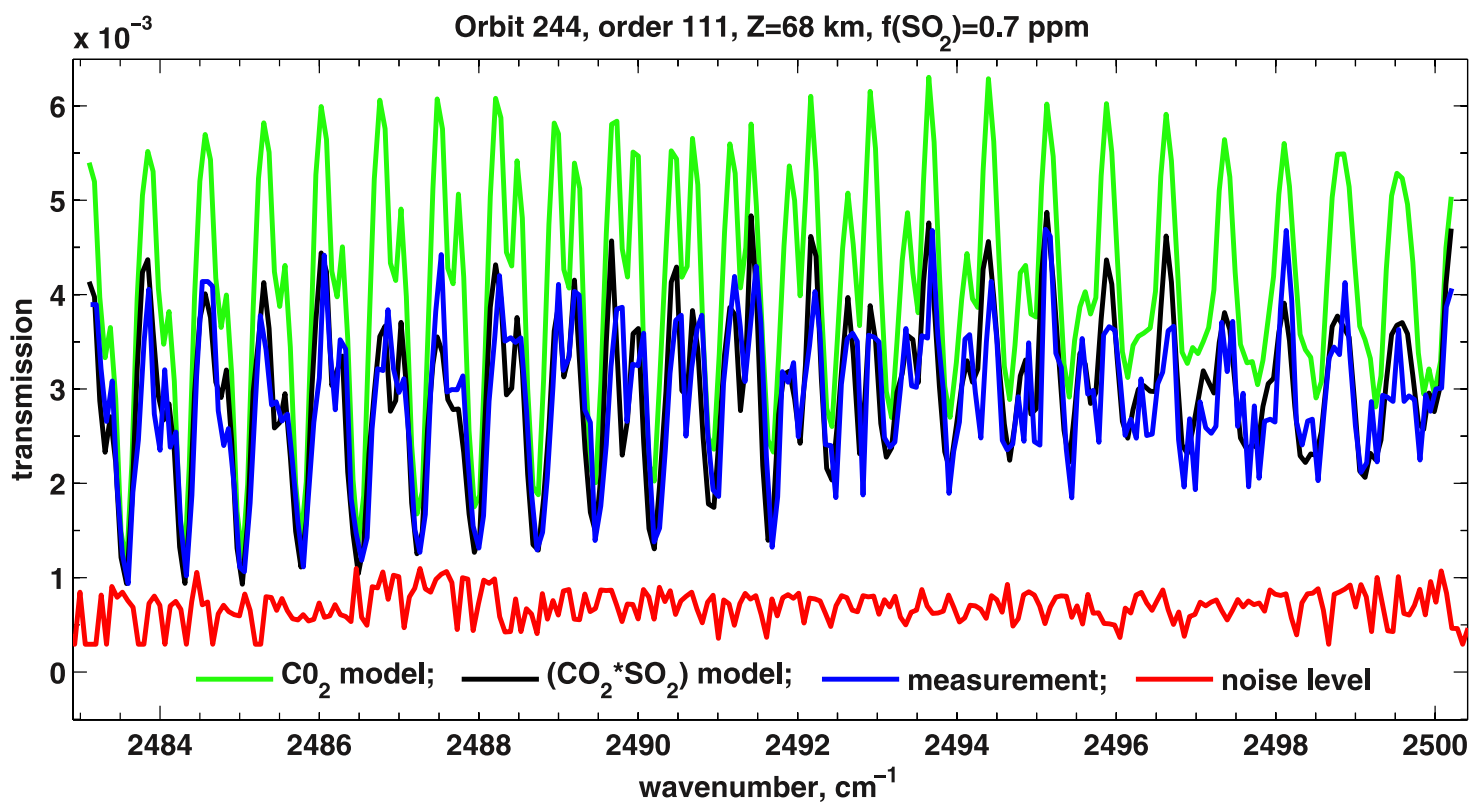

Figure 3. An example of transmission spectrum measured during an occultation on the orbit 244 at the altitude of $68 \mathrm{~km}$ is presented for the echelle order 111 (blue curve) with level of noise (red curve). Simulated spectrum of combined transmission $T_{\bmod }(\nu, z)=T_{\mathrm{CO} 2 \mathrm{SO} O}^{\text {ord }}(\nu, z) T_{\tau}(\nu, z)$ (see step 5 of the fitting algorithm) corresponds to the best fit of $0.7 \mathrm{ppm} \mathrm{SO}_{2}$ mixing ratio (black curve). Also, a fit in which $\mathrm{SO}_{2}$ absorption is forced to be zero and only the $\mathrm{CO}_{2}$ absorption remains $T_{\bmod }^{C O 2}(\nu, z) T_{\tau}(\nu, z)$ is shown by the green curve for the reference.

both parts of the spectrometer slit (see above). For the six occultations selected in present study the spectra measured in the two bins coincide within $10 \%$. It means that for these occultations the slit is kept nearly parallel to the limb, and we have averaged spectra from the two bins. For the remaining observations the slit cannot be considered parallel to the limb; more sophisticated geometry calculations and appropriate data processing for this case will be addressed to a future paper about SOIR performance.

\subsection{Data Analysis}

[19] Figure 3 displays a transmission spectrum measured at the altitude of $68 \mathrm{~km}$ during the occultation at orbit 244 (blue line). The spectrum is compared with a synthetic spectra of $\mathrm{CO}_{2}\left(T_{\bmod }^{\mathrm{CO}}(\nu, z) T_{\tau}(\nu, z)\right)$ and of combined $\mathrm{CO}_{2} * \mathrm{SO}_{2}\left(T_{\text {mod }}(\nu, z)\right)$ with retrieved optimal values of $n_{\mathrm{CO} 2}$ and $f_{\mathrm{SO} 2}$ as described above. The observed transmission is of the order of $0.3 \%$ only: the solar flux is highly attenuated, mainly by aerosols, with a horizontal optical thickness $\tau_{a} \approx 5.8$. The two synthetic spectra (for $\mathrm{CO}_{2}$ and $\mathrm{CO}_{2} * \mathrm{SO}_{2}$ ), which are built to mimic the observations, contain an aerosol attenuation, and the contribution of the adjacent orders, not completely eliminated by the AOTF function. This contribution amounts to $\approx 50 \%$ of the transmission in the main order observed.

[20] The signature of $\mathrm{SO}_{2}$ in the measured spectrum may be extracted by dividing the observed transmission by the $\mathrm{CO}_{2}$ simulation using:

$$
T_{\text {data }}^{S O 2}(\nu, z)=\frac{T_{\text {data }}(\nu, z)}{T_{\bmod }^{C O 2}(\nu, z) T_{\tau}(\nu, z)}
$$

and comparing the result with what is obtained using the simulated transmission:

$$
T_{\bmod }^{S O 2}(\nu, z)=\frac{T_{\bmod }(\nu, z)}{T_{\bmod }^{C O 2}(\nu, z) T_{\tau}(\nu, z)}
$$

This is illustrated in Figure 4. The resulting model transmission of $\mathrm{SO}_{2}$ is slightly different from the one displayed on Figure 1, because here the contribution of adjacent orders leaking through the AOTF orders is taken into account.

[21] An alternate estimation of $\mathrm{SO}_{2}$ contents was performed by comparing the measured $\mathrm{SO}_{2}$ transmission spectrum (equation 5) with the simulated one (equation 6) using a "scatter plot" where each point has for x coordinate $T_{\bmod }^{S O 2}$ $(\nu, z)$, and for $\mathrm{y}$ coordinate the $T_{\text {data }}^{S O 2}(\nu, z)$ (Figure $5 \mathrm{a}$ and equation (4)). The same exercise was performed with differential transmission $d T$, where $d T=T-\operatorname{average}(T(\nu))$ (Figure $5 \mathrm{~b}$ ), where the average value is a sliding average over $1 \mathrm{~cm}^{-1}$ along the whole $2484-2500 \mathrm{~cm}^{-1}$ range. When the slope on the plot is one at some variable parameter $f_{\mathrm{SO} 2}$, it means that the $\mathrm{SO}_{2}$ mixing ratio during the measurement is equal (or very near) to this $f_{\mathrm{SO} 2}$. The slope is found using least squares method. In the example shown, the slope is $k=0.94 \pm 0.20$ for $T$, and $k=0.90 \pm$ 0.16 for $d(T)$.

\subsection{Results}

[22] Vertical profiles of the sulfur dioxide mixing ratio are presented in Figure 6, together with aerosol slant optical thickness retrieved from the same measurement sequences as described above. Sometimes the fitting process does not allow finding a distinct minimum; in such cases only upper 


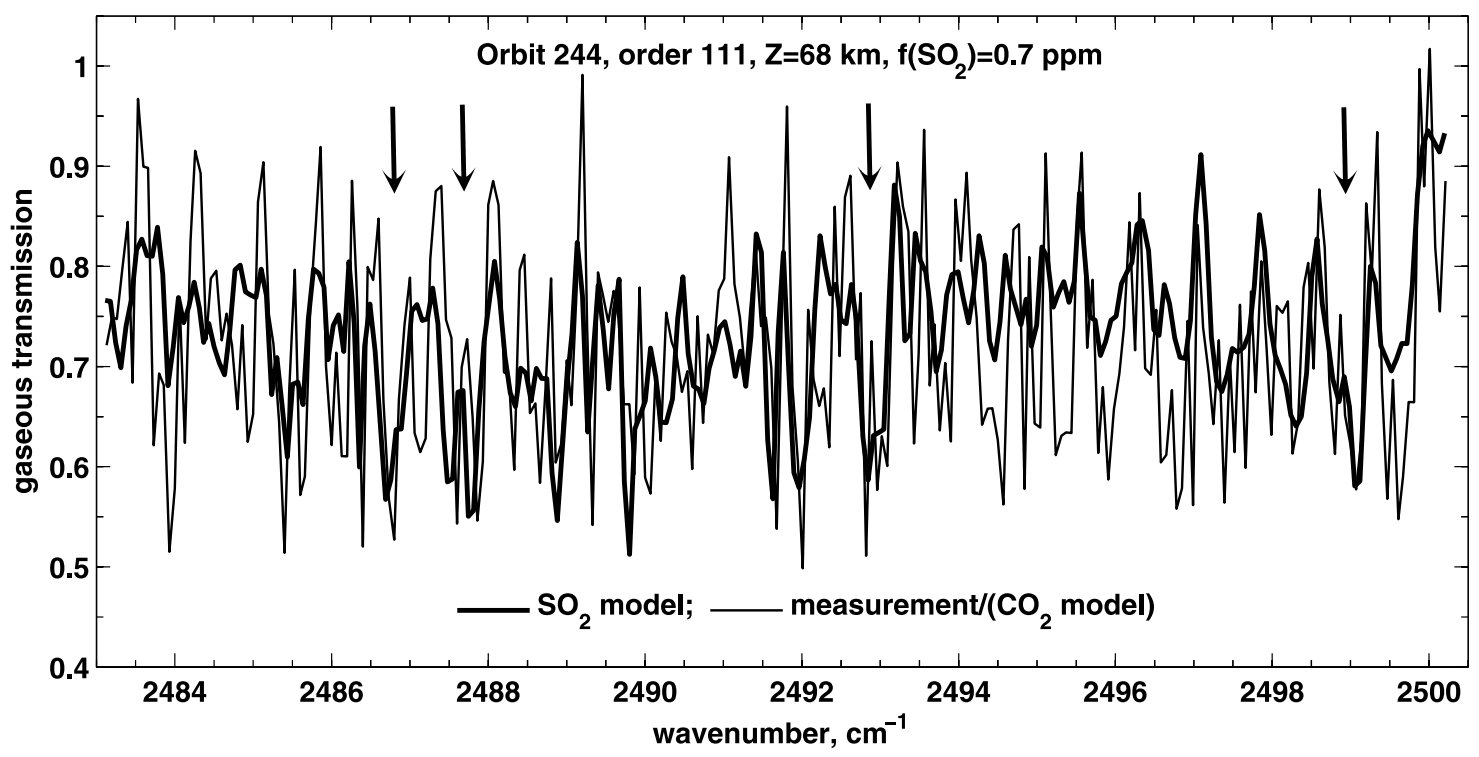

Figure 4. $\mathrm{SO}_{2}$ spectrum $T_{\text {data }}^{\mathrm{SO}}(\nu, z)$ (thin curve) retrieved from the same measured spectrum as in Figure 3 following equation (5) is compared with $\mathrm{SO}_{2}$ synthetic model $T_{\bmod }^{\mathrm{SO}}(\nu, z)$ (thick curve) following equation (6). Arrows mark the most prominent absorption features of sulfur dioxide. Only the gaseous transmission without contribution of aerosol extinction is presented.

limits of the $\mathrm{SO}_{2}$ abundance can be found (indicated by triangles). All the remaining points signify a positive detection with error bars. For all four high-latitude occultations available $\left(69^{\circ}-88^{\circ} \mathrm{N}\right)$ about $0.1 \mathrm{ppm}$ of $\mathrm{SO}_{2}$ is detected at the level of $70 \mathrm{~km}$, rapidly decreasing with a scale height of $H_{\mathrm{SO} 2}=1 \pm 0.4 \mathrm{~km}$ above. At low latitudes $\left(23^{\circ}-30^{\circ} \mathrm{N}\right)$ we detect significantly higher contents of about $1-3 \mathrm{ppm}$ and $H_{\mathrm{SO} 2}=3 \pm 1 \mathrm{~km}$. We used only the detected $\mathrm{SO}_{2}$ values to estimate the scale height; upper limits were not taken into account.

[23] The clouds top level seems to be a bit higher at low latitudes where mixing ratio of $\mathrm{SO}_{2}$ is found larger. The altitude where $\tau_{\mathrm{a}}=1$, a possible definition of clouds top level, is found to be of the order $75-76 \mathrm{~km}$ for latitudes $>69^{\circ}$ and $83 \mathrm{~km}$ for latitudes $23^{\circ}$ and $30^{\circ}$. Usually the clouds top is known to be at a lower altitude for high latitudes [Crisp, 1986]. It must be recognized that the clouds top is usually defined with a vertical depth of unity, at a much lower level than where the horizontal optical thickness is $\tau_{\mathrm{a}}=1$. In fact, at this level we probe the upper haze, which stands above the main clouds.

[24] In transmission we are sensitive to the total slant density of $\mathrm{SO}_{2}$ molecules, and not to the mixing ratio. This is why we would not be able to see $\mathrm{SO}_{2}$ at higher
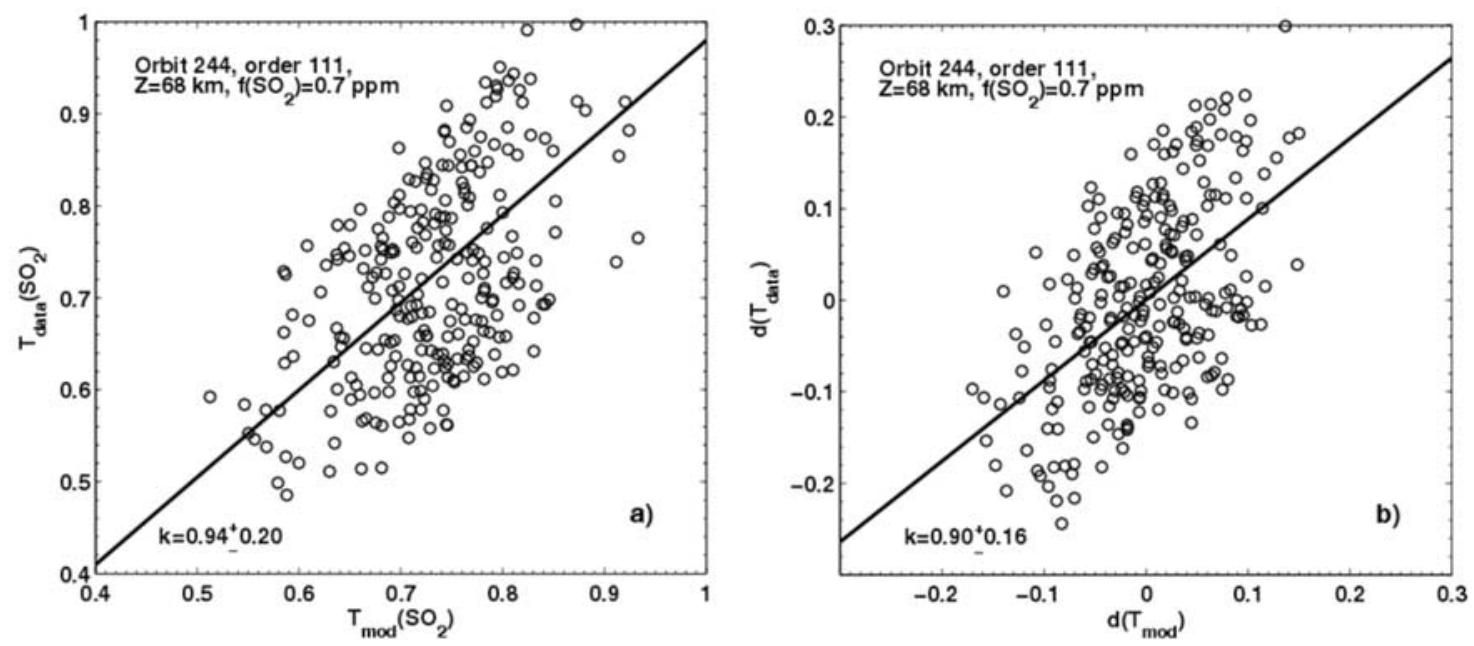

Figure 5. "Scattered plots" illustrating the retrieval of $\mathrm{SO}_{2}$ transmission are presented for the same measurements as in Figures 3 and 4. (a) The measured transmission $T_{\text {data }}^{S O 2}$ plotted versus the modeled one $T_{\mathrm{mod}}^{\mathrm{SO} 2}$, with a linear regression of this dependence (solid line). (b) The transmission $d T$, where $d T=T-$ average $(T)$ is plotted in the same manner. When the slope of the linear approximation $k$ is close to unity, the measured and theoretical $\mathrm{SO}_{2}$ contents are equal to each other (or very near). 


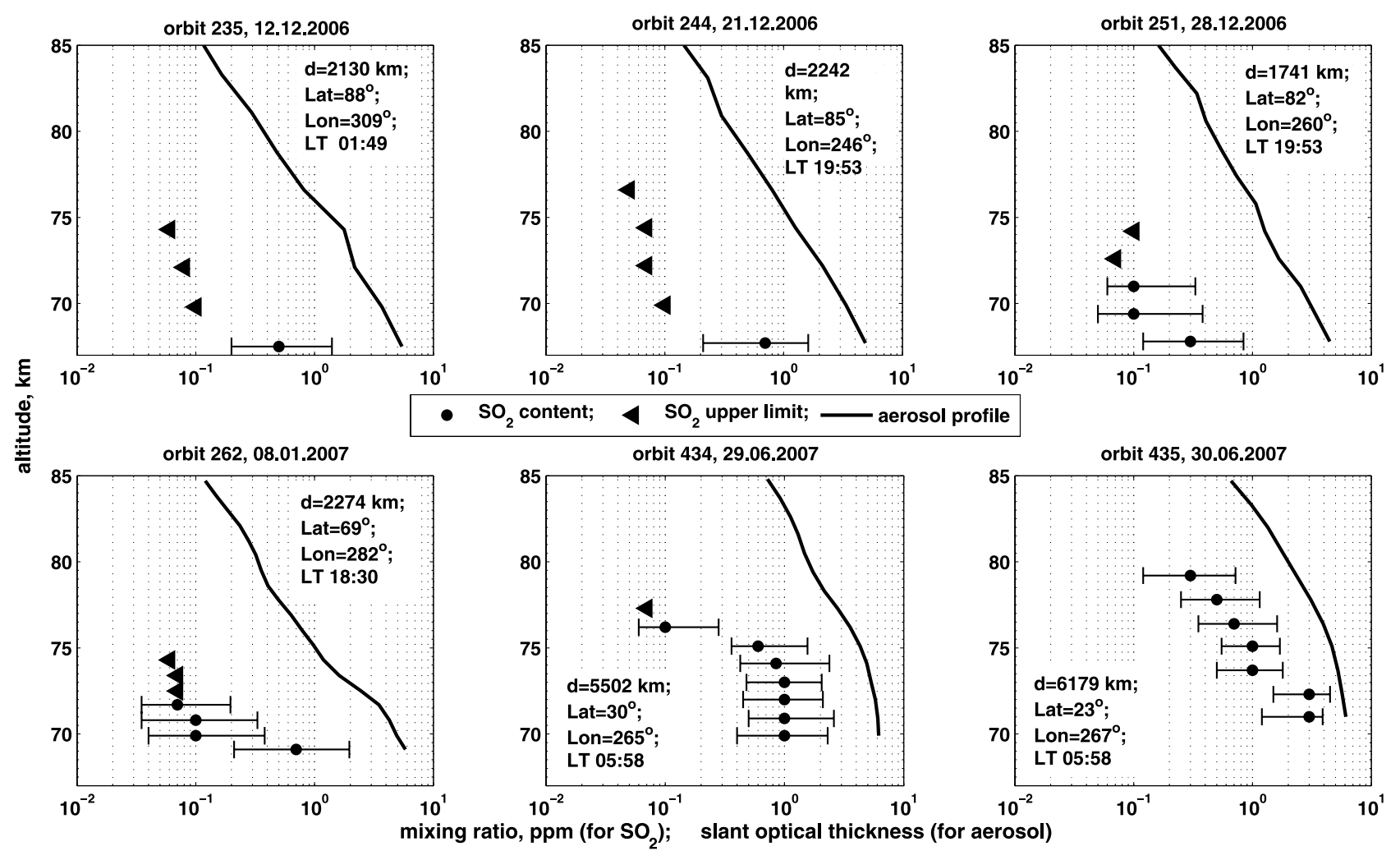

Figure 6. Vertical profiles of $\mathrm{SO}_{2}$ mixing ratio retrieved from all analyzed occultations (points with error bars) together with aerosol profiles (solid curves). Triangles denote the point where only the upper limits of the $\mathrm{SO}_{2}$ detection. The conditions of observations are indicted on the plots: d, distance to limb; Lat, latitude; Lon, longitude; LT, local time (see Table 1).

altitudes, even if the $\mathrm{SO}_{2}$ mixing ratio would be $>1 \mathrm{ppmv}$ above $75 \mathrm{~km}$.

\section{Uncertainties}

[25] There are several aspects that impact on the accuracy of retrieved results. Some of them deal with specific features of the spectrometer and some others with uncertainties of the observation geometry.

[26] The signal/noise ratio (SNR) of the instrument is about $10^{3}$ for solar spectrum outside the atmosphere in the center of diffraction orders 111-112. On the edges of the detector SNR decreases by a factor of 4-5 due to combined effect of AOTF passband and echelle blaze functions. The extinction by aerosol and $\mathrm{CO}_{2}$ at the altitude of $68-70 \mathrm{~km}$ (where $\mathrm{SO}_{2}$ is detected) decreases the signal by a factor of $5 \times 10^{-3}$. The resulting SNR effective for the altitude range of $\mathrm{SO}_{2}$ detection varies from 2 to 3 in the center of the detector to $10-15$ at the edges. These uncertainties for each pixel are taken into account as $\sigma_{i}$ in equation (4), and they are translated into $\sim 40 \%$ of random error of retrieved $\mathrm{SO}_{2}$ abundance.

[27] Systematic uncertainties considered are AOTF calibrations (different for the two parts of the slit), and altitude determination. The different AOTF calibrations [Mahieux et al., 2008] are minimized by averaging spectra from the two bins and can be estimated as $\sim 10 \%$ of relative error in the final gaseous content. The altitude uncertainties depend on the distance of the spacecraft to the limb $( \pm 0.5 \mathrm{~km}$ at
$2000 \mathrm{~km}$ and $\pm 2 \mathrm{~km}$ at $6000 \mathrm{~km}$ ); also we have neglected the atmospheric refraction (see above). However, for the retrieval of the mixing ratio the altitude uncertainty results in extraction of $\mathrm{CO}_{2}$ local density with errors $\sim 5 \%$. Summarizing all mentioned uncertainties we obtain errors of sulfur dioxide mixing ratio of about $50-70 \%$.

\section{Discussions}

[28] The measurements of sulfur dioxide above clouds were performed during almost 40 years (Figure 7 and Table 2) with some gaps. Summarizing the history of $\mathrm{SO}_{2}$ observations on Venus clouds top, an immediate conclusion is that the SOIR measurements indicate higher mixing ratios by a factor 5 to 25 with respect to all previous measurements. The solar occultation measurements are made at the terminator of the planet; that is, around one half of the optical path is in the shade, and another is sunlit. Most of previous nadir and limb observations, with the exception Venera 15 IR measurements were performed in the UV range on the dayside of the planet. The increased contents of $\mathrm{SO}_{2}$ measured on the terminator may be explained by its photochemical behavior. Indeed, the photochemical lifetime of $\mathrm{SO}_{2}$ exposed to sun light at $68-70 \mathrm{~km}$ altitude is $\sim 3 \times$ $10^{3} \mathrm{~s}$ (i.e., $1 \mathrm{~h}$ ) [Mills et al., 2007], and its contents should depend on local time. However, other photochemical cycles in which the $\mathrm{SO}_{2}$ is involved are more complicated: with UV solar light $\mathrm{SO}_{2}$ is rapidly produced again from $\mathrm{SO}$, and the timescale for net loss of $\mathrm{SO}_{2}$ via oxidation to $\mathrm{SO}_{3}$ 


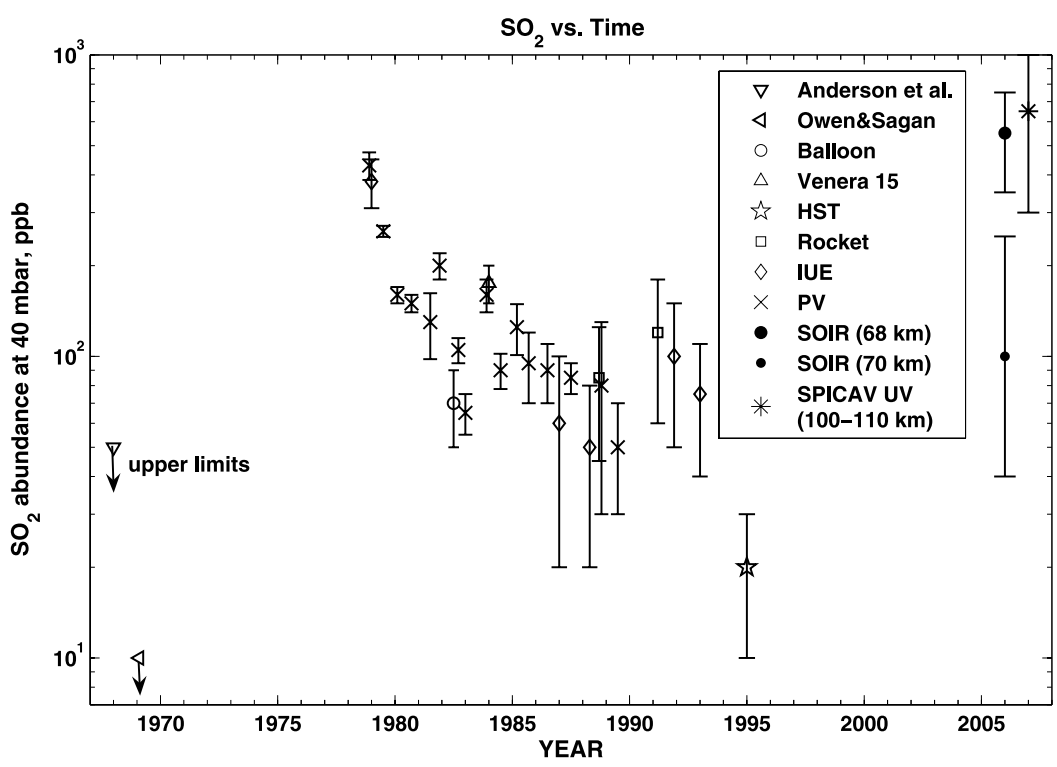

Figure 7. Measurements of $\mathrm{SO}_{2}$ on Venus above clouds, available from 1969 up to now (see Table 2). The $\mathrm{SO}_{2}$ content in ppb volume is considered at the level of 40 mbar ( $\sim 69 \mathrm{~km}$ of altitude). SOIR results indicate values for 68 and $70 \mathrm{~km}$ (only at high latitudes) and SPICAV UV results were derived from 100 to $110 \mathrm{~km}$.

is much longer, $10^{6}-10^{7} \mathrm{~s}$ [Winick and Stewart, 1980; Krasnopolsky and Pollack, 1994; Pernice et al., 2004]. These estimations for the lifetime depends on the column abundance of $\mathrm{SO}_{2}$ and the production rate for $\mathrm{SO}_{3}$, both of which are not well constrained.

[29] Comparing SOIR results on morning and evening terminators (see Table 1 and Figure 6), for morning occultations (at low latitudes) we measured $\sim 1 \mathrm{ppm}$ of $\mathrm{SO}_{2}$ mixing ratio while in the evening (high latitudes) $\sim 0.1 \mathrm{ppm}$ is detected at $70 \mathrm{~km}$ of altitude. Unfortunately, at present we do not have considerable statistics of observations to compare morning and evening occultations at similar latitudes. An extensive set of daytime and nighttime $\mathrm{SO}_{2}$ measurements was obtained by Fourier spectrometer (FS) on Venera 15. A strong latitude dependence of $\mathrm{SO}_{2}$ was retrieved from $20 \mathrm{ppb}$ at the equator up to $0.5 \mathrm{ppm}$ in polar regions [Zasova et al., 1993], but diurnal cycle dependencies were not analyzed.

[30] Regarding the altitude distribution of $\mathrm{SO}_{2}$, on the average SOIR measurements indicate a scale height of $1 \pm$
$0.4 \mathrm{~km}$ for polar measurements and $3 \pm 1 \mathrm{~km}$ at low latitudes at the altitude about $70 \mathrm{~km}$. The latter is comparable with the scale height retrieved by Venera $15 \mathrm{FS}$ at $69 \mathrm{~km}$ [Zasova et al., 1993]. For polar regions the scatter of Venera 15 scale heights is large, data being clustered around $1 \mathrm{~km}$ and 4-6 km. The estimations of scale height from PV ultraviolet measurements [Esposito et al., 1984] ranges from 1.5 to $4-5 \mathrm{~km}$; the IUE measurements [Na et al., 1990] are consistent with a scale height of $3 \pm 1 \mathrm{~km}$. Our data are not in conflict with these previous measurements. The peculiarities of the solar occultation technique are operations at the planet terminator, hence, at local morning or evening, and a significant horizontal optical path, reaching $450 \mathrm{~km}$ at $70 \mathrm{~km}$. Therefore, SOIR measurements might reflect evening/morning, and also horizontal inhomogeneities, the latter may be associated with small-scale haze structures. VIRTIS has observed such structures at a scale down to few kilometers [Piccioni, 2008].

[31] Several hypothesis have been put forward in order to explain the amazing evolution of sulfur dioxide content

Table 2. List of Previous Detections of Sulfur Dioxide Above Venus' Clouds by Several Methods and in Several Spectral Ranges ${ }^{\mathrm{a}}$

\begin{tabular}{|c|c|c|c|}
\hline Reference & Instrument & Spectral Range (nm) & $\mathrm{SO}_{2}$ Content (ppb) \\
\hline Anderson et al. [1969] & Rocket & $200-300$ & $<50$ \\
\hline Owen and Sagan [1972] & $\mathrm{OAO}$ & $200-360$ & $<10$ \\
\hline Esposito et al. $[1988]$ & UV spectrometer (PV) & $200-320$ & $50-400$ \\
\hline Na et al. [1990] & UV spectrometer (IUE) & $200-220$ & $50-380$ \\
\hline Parisot et al. [1986] & Balloon & $200-320$ & 70 \\
\hline $\begin{array}{l}\text { Moroz et al. }[1985] ; \\
\quad \text { Zasova et al. }[1993]\end{array}$ & $\begin{array}{l}\text { Fourier Spectrometer } \\
\text { (Venera 15) }\end{array}$ & $7350,8700,19270$ & 200 \\
\hline McClintock et al. [1994] & Rocket & $190-230$ & $80-120$ \\
\hline Na and Esposito [1995] & HST & $207-216$ & 20 \\
\hline Bertaux et al. [2008] & SPICAV UV (VEX) & $200-320$ & $300-1000$ \\
\hline This paper & SOIR (VEX) & 4000 & $100-550$ \\
\hline
\end{tabular}

${ }^{\mathrm{a}} \mathrm{SO}_{2}$ content correspond to altitude of $\sim 69 \mathrm{~km}$ except SPICAV UV results that were derived from 100 to $110 \mathrm{~km}$. 
above Venus clouds on a timescale of tens of years from 1967 to 1995 (Figure 7). After a sharp increase between 1967 and 1979, a stable decline down to $\sim 20 \mathrm{ppb}$ at 1995 was observed, with values close to upper limits of 1967. Three possible explanations of such behavior were recently recalled by Mills et al. [2007]: active volcanism [Esposito, 1984], changes in the effective eddy diffusion within the cloud layers [Krasnopolsky, 1986, p. 147], and changes in atmospheric dynamics [Clancy and Muhleman, 1991]. The volcano hypothesis uses the volcanic eruption as a source of buoyancy that allows the abundant $\mathrm{SO}_{2}$ below the Venus clouds to break through the stable upper cloud layer. The entrained $\mathrm{SO}_{2}$ is then observable remotely at the cloud top in the UV. Similarly, because the observed $\mathrm{SO}_{2}$ mixing ratio may differ by as much as 4 orders of magnitude from the base to the top of the cloud layers [Bertaux et al., 1996; Esposito et al., 1997], a small change in the effective eddy diffusion within the cloud layers may significantly alter the cloud top abundance of $\mathrm{SO}_{2}$ [Krasnopolsky, 1986, p. 147]. The average $\mathrm{SO}_{2}$ abundance below the clouds varies probably much more slowly, connected to the evolution of volcanic activity over geologic timescales [Fegley et al., $1997 \mathrm{a}]$.

[32] Large values of $\mathrm{SO}_{2}$ (up to 2 ppm) observed by SOIR on Venus Express in a limited set are supported by recent microwave observations by Sandor et al. [2007], indicating also a large variability of $\mathrm{SO}_{2}$, and by SPICAV UV stellar occultations with retrieval from 0.3 to 1 ppmv of the gas at 100-110 km [Bertaux et al., 2008]. At present it would be premature to conclude that in 2004-2007 we observe another global increase of $\mathrm{SO}_{2}$ contents, like one suspected in between 1970 and 1977 or a leftover of such an increase in the past. Sulfur dioxide content at Venus' clouds top might express significant variations in the haze cover. Sulfuric acid droplets are a potential reservoir of $\mathrm{SO}_{2}$, and a surge of $\mathrm{SO}_{2}$ may results from an increased evaporation of these droplets, triggered by a temperature change of dynamical origin.

[33] Further monitoring of $\mathrm{SO}_{2}$ by SOIR and SPICAV at high altitudes may clarify these dependences.

[34] Acknowledgments. We thank our collaborators of the three institutes for the design and fabrication of the SOIR instrument, which was mainly built in Belgium by OIP Company, under the direction of IASB-BIRA (IASB-BIRA/Belgium, Service d'Aéronomie/France, and IKI/ Moscow). Russian team acknowledges RFBR grant 06-02-72563. Belgium team was supported by the Belgian Federal Science Policy Office and the European Space Agency (ESA, PRODEX program, contracts C 90268 , 90113, and 17645). Procurement of AOTF was funded by CNES.

\section{References}

Anderson, R. C., J. G. Pipes, A. L. Broadfoot, and L. Wallace (1969), Spectra of Venus and Jupiter from 1800 to 3200 A, J. Atmos. Sci., 26, 874-888, doi:10.1175/1520-0469(1969)026<0874:SOVAJF $>2.0$.CO;2.

Barker, E. S. (1979), Detection of $\mathrm{SO}_{2}$ in the UV spectrum of Venus, Geophys. Res. Lett., 6(2), 117-120, doi:10.1029/GL006i002p00117.

Bertaux, J.-L., T. Widemann, A. Hauchecorne, V. I. Moroz, and A. P. Ekonomov (1996), VEGA 1 and VEGA 2 entry probes: An investigation of local UV absorption $(220-400 \mathrm{~nm})$ in the atmosphere of Venus $\left(\mathrm{SO}_{2}\right.$, aerosols, cloud structure), J. Geophys. Res., 101, 12,709-12,745, doi:10.1029/96JE00466.

Bertaux, J.-L., et al. (2007), SPICAV on Venus express: Three spectrometers to study the Global structure and composition of the Venus atmosphere, Planet. Space Sci., 55, 1673-1700, doi:10.1016/j.pss.2007.01.016.

Bertaux, J.-L., et al. (2008), SPICAV/SOIR on board Venus Express: An overview of two years of observations, paper presented at 37th COSPAR Scientific Assembly, Montreal, Canada, July 13-21.
Bézard, B., J.-P. Baluteau, A. Marten, and N. Coron (1987), The ${ }^{12} \mathrm{C} /{ }^{13} \mathrm{C}$ and ${ }^{16} \mathrm{O} /{ }^{18} \mathrm{O}$ ratios in the atmosphere of Venus from high-resolution $10-\mu \mathrm{m}$ spectroscopy, Icarus, 72(3), 623 - 634, doi:10.1016/0019-1035(87)90057-1. Clancy, R. T., and D. O. Muhleman (1991), Long-term (1979-1990) changes in the thermal dynamical and compositional structure of the Venus mesosphere as inferred from microwave spectral observations of ${ }^{12} \mathrm{CO},{ }^{13} \mathrm{CO}$ and $\mathrm{C}^{18} \mathrm{O}$, Icarus, 89, 129-146, doi:10.1016/0019-1035(91) 90093-9.

Conway, R. R., R. P. Mccoy, C. A. Barth, and A. L. Lane (1979), IUE detection of sulfur dioxide in the atmosphere of Venus, Geophys. Res. Lett., 6(7), 629-631, doi:10.1029/GL006i007p00629.

Crisp, D. (1986), Radiative forcing of the Venus mesosphere. I - Solar fluxes and heating rates, Icarus, 67, 484-514, doi:10.1016/00191035(86)90126-0

Esposito, L. W. (1984), Sulfur dioxide: Episodic injection shows evidence for active Venus volcanism, Science, 223, 1072-1074, doi:10.1126/ science.223.4640.1072.

Esposito, L. W., J. R. Winick, and A. I. Stewart (1979), Sulfur dioxide in the Venus atmosphere: Distribution and implications, Geophys. Res. Lett., 6(7), 601-604, doi:10.1029/GL006i007p00601.

Esposito, L. W., M. Copley, R. Eckert, L. Gates, A. I. F. Stewart, and H. Worden (1988), Sulfur dioxide at the Venus cloud tops, 1978-1986, J. Geophys. Res., 93, 5267-5276, doi:10.1029/JD093iD05p05267.

Esposito, L. W., J.-L. Bertaux, V. Krasnopolsky, V. I. Moroz, and L. V. Zasova (1997), Chemistry of lower atmosphere and clouds, in Venus II, edited by S. W. Bougher, D. M. Hunten, and R. J. Phillips, pp. 415-458, Univ. of Ariz. Press, Tucson.

Fedorova, A., et al. (2008), HDO and $\mathrm{H} 2 \mathrm{O}$ vertical distributions and isotopic ratio in the Venus mesosphere by Solar Occultation at Infrared spectrometer on board Venus Express, J. Geophys. Res., doi:10.1029/ 2008JE003146, in press.

Fegley Jr., B., G. Klingelhofer, K. Lodders, and T. Widemann (1997a), Geochemistry of surface-atmosphere interactions on Venus, in Venus II, edited by S. W. Bougher, D. M. Hunten, and R. J. Phillips, pp. 591-636, Univ. of Ariz. Press, Tucson.

Jenkins, E. B., D. C. Morton, and A. V. Sweigart (1969), Rocket spectra of Venus and Jupiter from 2000 to $3000 \AA$, Astrophys. J., 157, 913-924, doi:10.1086/150123.

Korablev, O. I., J.-L. Bertaux, I. I. Vinogradov, Y. K. Kalinnikov, D. Nevejans, E. Neefs, T. Le Barbu, and G. Durry (2004), Compact high-resolution echelle-AOTF NIR spectrometer for atmospheric measurements, in Proceedings of the 5th ICSO, Eur. Space Agency Spec. Publ., ESA SP-554, $73-80$.

Krasnopolsky, V. A. (1986), Photochemistry of the Atmosphere of Mars and Venus, 147 pp., Springer, Berlin.

Krasnopolsky, V. A., and J. B. Pollack (1994), $\mathrm{H}_{2} \mathrm{O}-\mathrm{H}_{2} \mathrm{SO}_{4}$ system in Venus' clouds and $\mathrm{OCS}, \mathrm{CO}$, and $\mathrm{H}_{2} \mathrm{SO}_{4}$ profiles in Venus' troposphere, Icarus, 109, 58-78, doi:10.1006/icar.1994.1077.

Mahieux, A., et al. (2008), In-flight performance and calibration of SPICAV SOIR on board Venus Express, Appl. Opt., 47(13), 2252-2265, doi:10.1364/AO.47.002252.

McClintock, W. E., C. A. Barth, and R. A. Kohnert (1994), Sulfur dioxide in the atmosphere of Venus, Icarus, 112, 382-388, doi:10.1006/ icar.1994.1192.

Mills, F. P., L. W. Esposito, and Y. L. Yung (2007), Atmospheric composition, chemistry, and clouds, in Exploring Venus as a Terrestrial Planet, Geophys. Monogr. Ser., vol. 176, edited by L. W. Esposito, E. R. Stofan, T. E. Cravens, pp. 73-100, AGU, Washington, D. C

Moroz, V. I., and L. V. Zasova (1997), VIRA-2: A review of inputs for updating the Venus International Reference Atmosphere, Adv. Space Res., 19(8), 1191-1201, doi:10.1016/S0273-1177(97)00270-6.

Moroz, V. I., et al. (1985), Venera 15 and Venera 16 infrared experiment. 4. Preliminary results of spectral analyses in the region of $\mathrm{H}_{2} \mathrm{O}$ and $\mathrm{SO}_{2}$ absorption bands, Cosmic Res., Engl. Transl., 23(2), 202-211.

$\mathrm{Na}, \mathrm{C}$. Y., and L. W. Esposito (1995), UV observations of Venus with HST (abstract), Bull. Am. Astron. Soc., 27, 1071.

Na, C. Y., L. W. Esposito, and T. E. Skinner (1990), International Ultraviolet Explorer observation of Venus $\mathrm{SO}_{2}$ and SO, J. Geophys. Res. 95(D6), 7485-7491, doi:10.1029/JD095iD06p07485.

Na, C. Y., L. W. Esposito, W. E. McClintock, and C. A. Barth (1994), Sulfur dioxide in the atmosphere of Venus, II. Modeling results, Icarus, 112, 389-395, doi:10.1006/icar.1994.1193

Nevejans, D., et al. (2006), Compact high-resolution spaceborne echelle grating spectrometer with acousto-optical tunable filter based order sorting for the infrared domain from 2.2 to $4.3 \mu \mathrm{m}, \mathrm{Appl}$. Opt., 45(21), 5191-5206, doi:10.1364/AO.45.005191.

Owen, T., and C. Sagan (1972), Minor constituents in planetary atmospheres: Ultraviolet spectroscopy from the Orbiting Astronomical Observatory, Icarus, 16, 557-568, doi:10.1016/0019-1035(72)90102-9. 
Parisot, J. P., P. Rigaud, and D. Huguenin (1986), Balloon observations of Venus from 200 to $320 \mathrm{~nm}$, Astron. Astrophys., 166, 333-336.

Pernice, H., et al. (2004), Laboratory evidence for a key intermediate in the Venus atmosphere: Peroxychloroformyl radical, Proc. Natl. Acad. Sci. U. S. A., 101, 14,007-14,010, doi:10.1073/pnas.0405501101.

Piccioni, G. (2008), Observations of Venus by VIRTIS aboard Venus Express, paper presented at 37th COSPAR Scientific Assembly, Montréal, Canada, 13-20 July.

Plat, U. (1994), Differential optical absorption spectroscopy, in Air Monitoring by Spectroscopic Techniques, Chem. Anal. Ser., vol. 127, edited by M. W. Sigrist, pp. 27-84, John Wiley, New York.

Rothman, L. S., et al. (2005), The HITRAN 2004 molecular spectroscopic database, J. Quant. Spectrosc. Radiat. Transfer, 96(2), 139-204, doi:10.1016/j.jqsrt.2004.10.008.

Sandor, B. J., T. Clancy, G. H. Moriarty-Schieven (2007), SO and $\mathrm{SO}_{2}$ in the Venus mesosphere: Observations of extreme and rapid variation, paper presented at 3th DPS Meeting, Am. Astron. Soc., Orlando, Fla.

Stewart, A. I., D. E. Anderson, L. W. Esposito, and C. A. Barth (1979), Ultraviolet spectroscopy of Venus: Initial results from the Pioneer Venus orbiter, Science, 203, 777-779, doi:10.1126/science.203.4382.777.

Titov, D. V., et al. (2006), Venus Express: Scientific goals, instrumentation, and scenario of the mission, Cosmic Res., Engl. Transl., 44(4), 334-348, doi:10.1134/S0010952506040071.
Vandaele, A. C., et al. (2008), Composition of the Venus mesosphere measured by Solar Occultation at Infrared on board Venus Express, J. Geophys. Res., doi:10.1029/2008JE003140, in press.

Winick, J. R., and A. I. Stewart (1980), Photochemistry of $\mathrm{SO}_{2}$ in Venus' upper cloud layers, J. Geophys. Res., 85, 7849-7860, doi:10.1029/ JA085iA13p07849.

Yung, Y. L., and W. B. Demore (1982), Photochemistry of the stratosphere of Venus-Implications for atmospheric evolution, Icarus, 51(2), 199247, doi:10.1016/0019-1035(82)90080-X.

Zasova, L. V., V. I. Moroz, L. W. Esposito, and C. Y. Na (1993), SO2 in the middle atmosphere of Venus: IR measurements from Venera-15 and comparison to UV data, Icarus, 105(1), 92-109, doi:10.1006/icar.1993.1113.

Zasova, L. V., et al. (2006), Structure of Venusian atmosphere from surface up to $100 \mathrm{~km}$, Cosmic Res., Engl. Transl., 44(4), 364-383, doi:10.1134/ S0010952506040095.

D. Belyaev, A. Fedorova, and O. Korablev, IKI, 117997, 84/32 Profsoyuznaya Street, Moscow, Russia. (dbelyaev@iki.rssi.ru)

J.-L. Bertaux and F. Montmessin, Service d'Aéronomie du CNRS, BP 3 , F-91371 Verrières-le-Buisson, France.

R. Drummond, A. Mahieux, A.-C. Vandaele, and V. Wilquet, Belgian Institute for Space Aeronomy, 3 avenue Circulaire, B-1180 Brussels, Belgium. 